\title{
УДК 519.87
}

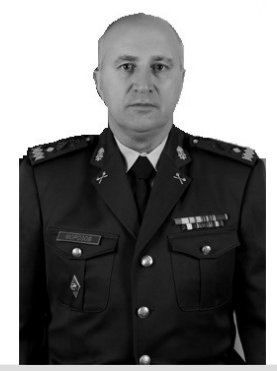

О. О. Морозов

\section{МЕТОДИКА ВИЗНАЧЕННЯ ПЕРІОДИЧНОСТІ ТЕХНІЧНОГО ОБСЛУГОВУВАННЯ ЗАСОБІВ СКЛАДНОЇ ТЕХНІЧНОЇ СИСТЕМИ}

У статті розглянуто задачу визначення періодичності технічного обслуговування засобів складної технічної системи, запропонована методика ї̈ розв'язання. Показано, щяо в умовах, коли засоби системи мають різні рівні надійності $i$, як наслідок, різні періодичності технічного обслуговування, забезпечення заданих режимів функиіонування системи потребує знаходження компромісного періоду обслуговування для всіх засобів. Пропонується обслуговувати засоби системи з періодичністю, що кратна періоду обслуговування найменш надійного засобу. Запропоновано вирішальне правило визначення періодичності обслуговування кожного засобу для визначення деякого допустимого значення коефімієнта його готовності та межі допустимого значення періоду обслуговування. Значення такого періоду визначається з того, щчо коефіцієнт готовності засобу буде не менше деякого допустимого значення.

Ключ о в $і$ сл о в а: складна технічна система, засоби системи, технічне обслуговування, періодичність технічного обслуговування, вирімальне правило, коефіцієнт готовності, режими функиіонування.

Постановка проблеми. Вирішуючи завдання визначення періодичності технічного обслуговування (ТО) складних технічних систем (СТС), зазвичай доводиться розв'язувати задачу визначення узгодженої (компромісної) періодичності обслуговування зразків (систем, комплексів) (далі - засобів), які входять до ії складу та забезпечують iі функціонування або застосування за призначенням. Такі засоби знаходяться у зв'язках, що утворюють цілісність, єдність, разом 3 тим вони різні за функціональним призначенням, мають відмінні показники надійності та, як наслідок, різні періодичності їх обслуговування. Узгодження періодичності ТО засобів має забезпечувати обгрунтування компромісної періодичності їх обслуговування. При цьому необхідно враховувати як режими функціонування (застосування) СТС, так і цикли застосування засобів системи. Також для заданого циклу застосування засобів необхідно забезпечувати заданий рівень готовності системи у цілому. Очевидно, що чим складніше система, тим складніше сформувати близький до оптимального (раціональний) план обслуговування іiі засобів.

Кожному iз засобів СТС відповідає індивідуальне (оптимальне) значення періодичності технічного обслуговування. Множина значень періодів ТО, яка відповідає множині засобів, що включаються до складу СТС, утворює таку сукупність циклів обслуговування, що практична іï реалізація є нераціональною. У зв'язку з цим $є$ необхідність упорядкування цієї сукупності шляхом знаходження компромісних, близьких до оптимальних, значень періодичності обслуговування всіх засобів системи. Очевидно, слід мати інструментарій, який би дозволяв визначати компромісну періодичність ТО засобів СТС, яка б забезпечувала необхідну готовність їх до застосування.

Аналіз останніх досліджень і публікацій. Аналіз постановок задач визначення періодичності обслуговування технічних засобів і підходів до їх розв'язання показує, що існує кілька підходів: моделювання процесів обслуговування, розрахункові, графічні та інші [1-5]. При цьому багато пропонованих підходів грунтуються на припущенні схожості характеристик надійності засобів та, як правило, таких, що незначно відрізняються періодичностями їх технічного обслуговування. Різними вважаються тривалості обслуговування таких засобів. Якщо ж СТС складається зі значної 
номенклатури засобів, взаємопов'язаних між собою, що визначають режими і результати ії функціонування, мають відмінні періодичність і тривалість обслуговування, то, як свідчать джерела [1, 2, 6, 7], відшукати суворе формальне рішення дуже складно. Визначення оптимальної періодичності обслуговування для кожного засобу системи не забезпечує оптимальність періодичності іiі обслуговування цими засобами, що на практиці призводить до необхідності коригування періодичності обслуговування засобів $[5,8]$.

Розв'язування задач 3 багатьма змінними потребує використання апарату математичного моделювання, що істотно ускладнює інтерпретацію результатів моделювання i ïx практичне використання [1, 6-8]. Для практики необхідний інструментарій знаходження компромісних, близьких до оптимальних, значень періоду обслуговування всіх засобів системи. Такий компроміс може відображати вирішальне правило, яке буде вводитися неформально і являти собою допустиме відхилення значень періодів обслуговування засобів від оптимальних значень.

Мета статті - розроблення методики визначення періодичності технічного обслуговування засобів складної технічної системи.

Виклад основного матеріалу. Процес застосування кожного із засобів СТС має циклічний характер. Кожен цикл може включати в себе роботу засобів у номінальному режимі і знаходження у вимкненому стані. Діаграма процесу застосування засобу зображена на рис. 1.

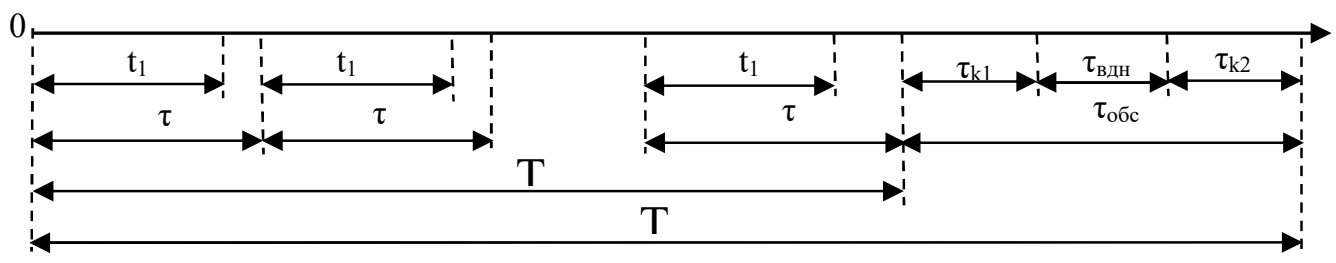

Рис. 1. Діаграма процесу застосування засобів СТС

Тут $\tau$ - тривалість циклу застосування засобу; $\mathrm{t}_{1}$ - тривалість роботи засобів у номінальному режимі з коефіцієнтом навантаження $\mathrm{k}=1$. Інтенсивність його відмов має значення $\lambda_{1}$.

На інтервалі $\mathrm{t}_{2}=\tau-\mathrm{t}_{1}$ засіб знаходиться у вимкненому стані. Інтенсивність відмов $\lambda_{2}$ при цьому згідно з даними довідника [9] буде $0<\lambda_{2} \ll \lambda_{1}$.

Для підтримання кожного засобу в працездатному стані періодично проводиться його технічне обслуговування, на що витрачається час $\tau_{\text {вє }}$. Також виконується поглиблений контроль його стану протягом часу $\tau_{\mathrm{k} 1}$ та проводяться регламентні роботи i відновлення працездатності засобу у разі виявлення відмови, на що витрачається час $\tau_{\text {вдн }}$. Після закінчення цих робіт проводиться контрольна перевірка його працездатності протягом часу $\tau_{\mathbf{k} 2}$. Контроль технічного стану виконується в умовах номінального режиму роботи засобу. Тому на інтервалах часу $\tau_{\mathbf{k} 1}$ та $\tau_{\mathbf{k} 2}$ інтенсивність відмов буде дорівнювати $\lambda_{1}$. Для проведення ремонтно-відновлювальних робіт засіб переводиться в "режим відпочинку”, що відповідає інтенсивності відмов $\lambda_{2}$. У зв'язку з цим загальну тривалість технічного обслуговування тобе можна визначити так [10]:

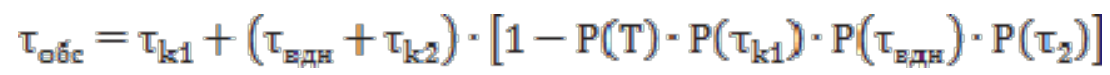

або

$$
\tau_{\text {oб́c }}={ }^{\prime} \tau_{k 1}+\tau_{\text {BAH }}+\tau_{k 2}-\left(\tau_{B}+\tau_{k 2}\right) \cdot P(T) \cdot P\left(\tau_{k 1}+\tau_{k 2}\right) \cdot P\left(\tau_{B A H}\right),
$$

де $\mathbf{P}(\mathrm{T}), \mathbf{P}\left(\tau_{\mathrm{k} 1}+\tau_{\mathrm{k} 2}\right), \mathbf{P}\left(\tau_{\text {вдн }}\right)$ - ймовірності безвідмовної роботи засобу на відповідних інтервалах часу.

Тривалість періоду обслуговування Т включає в себе множину $\mathbf{i}=\overline{1, n}$ циклів застосування засобу 3 тривалістю т кожний, тобто

$$
\mathrm{T}=\sum_{\mathrm{i}=1}^{\mathrm{n}} \tau_{\mathrm{i}}=\mathrm{T}_{1}+\mathrm{T}_{2}
$$




$$
T_{1}=\sum_{i=1}^{n} t_{1 i} ; \quad T_{2}=\sum_{i=1}^{n} t_{2 i}
$$

Тривалість циклу обслуговування засобу становить

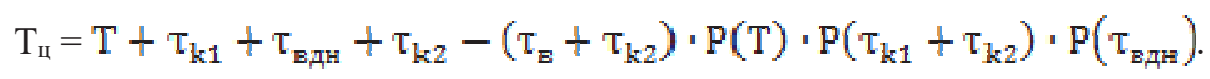

Ймовірність безвідмовної роботи засобу на інтервалі часу Т виражається так:

$$
P(T)=P_{1}\left(T_{1}\right) \cdot P_{2}\left(T_{2}\right)
$$

Для засобів СТС справедливим є твердження, що в них переважають раптові відмови, тому застосуємо експоненціальний закон розподілу відмов [9]. При цьому мають місце такі співвідношення:

$$
\begin{gathered}
\mathrm{P}_{1}\left(\mathrm{~T}_{1}\right)=\exp \left\{-\lambda_{1} \mathrm{~T}_{1}\right] ; \quad \mathrm{P}_{2}\left(\mathrm{~T}_{2}\right)=\exp \left\{-\lambda_{2} \mathrm{~T}_{2}\right] \\
\mathrm{P}\left(\tau_{\mathrm{k} 1}+\tau_{\mathrm{k} 2}\right)=\exp \left\{-\lambda_{1}\left(\tau_{\mathrm{k} 1}+\tau_{\mathrm{k} 2}\right)\right] ; \quad \mathrm{P}\left(\tau_{\mathrm{вд \mu}}\right)=\exp \left\{-\lambda_{2} \mathrm{~T}_{2}\right\}
\end{gathered}
$$

Час працездатного стану засобу $\mathrm{T}_{\text {me }}$ на інтервалі часу Т визначається за формулою

$$
T_{\text {me }}(T)=T_{\text {mc1 }}\left(T_{1}\right)+T_{m c 2}\left(T_{2}\right)=\int_{0}^{T_{11}^{1}} P_{1}(t) d t+\int_{0}^{T_{2}} P_{2}(t) d t .
$$

Організація експлуатації засобів передбачає визначення раціональних або оптимальних, в деякому сенсі, термінів технічного обслуговування, які забезпечують необхідну якість їх функціонування. Комплексним показником надійності є коефіцієнт готовності. Його значення з урахуванням формул (4) та (8) обчислюється за співвідношенням [9]

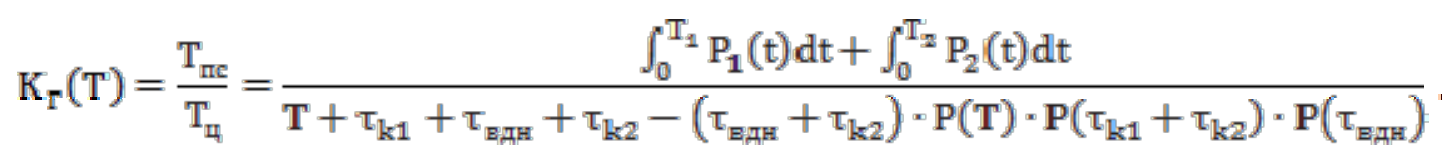

Аналіз функції $\mathrm{K}_{\Gamma}(\mathrm{T})$ свідчить, що за умов $\mathrm{T} \rightarrow 0$ та $\mathrm{T} \rightarrow \infty, \mathrm{K}_{\Gamma}(\mathrm{T}) \rightarrow 0$. Існує періодичність технічного обслуговування $\mathrm{T}^{*}$, за якої коефіцієнт $\mathrm{K}_{\mathrm{T}}\left(\mathrm{T}^{*}\right)$ досягає максимального значення. Задачу визначення оптимального періоду $\mathrm{T}^{*}$ обслуговування засобу запишемо у вигляді:

$$
\mathrm{T}^{*}=\operatorname{argmax}_{\mathrm{T}} \mathrm{K}_{\mathrm{T}}(\mathrm{T})
$$

Розглянутий підхід доцільно використовувати стосовно функціонально відокремлених засобів.

До складу СТС входить множина різних за функціональним призначенням і безвідмовністю засобів. Кожному з них відповідає індивідуальне оптимальне значення періодичності технічного обслуговування $\mathrm{T}_{\mathrm{i}}^{*}$. Множина значень $\mathrm{T}_{i}^{\text {है }}$, відповідна множині засобів, які входять до складу СТС, 
$1=\overline{1, n}$, утворює таку сукупність циклів обслуговування, що практична ії реалізація $\epsilon$ нераціональною. У зв'язку з цим необхідно упорядкувати цю сукупність шляхом знаходження компромісних, близьких до оптимальних, значень періодичності обслуговування всіх засобів системи. Такий компроміс $є$ відображенням вирішального правила, яке вводиться неформально і визначає допустиме відхилення значень періодів обслуговування засобів від оптимальних значень $T_{i}^{8}$.

Прийнятною, з погляду на впорядкування термінів обслуговування засобів, $\epsilon$ кратність періодів їх обслуговування [10]. Різні засоби (або групи засобів) будуть обслуговуватися з різною періодичністю:

$$
\left.\mathrm{T}_{\min }^{*}, 2 \mathrm{~T}_{\min }^{*}, \ldots, \mathrm{mT}_{\min }^{*}\right\}
$$

де $\mathrm{T}_{\operatorname{mim}}^{8}$ - оптимальне значення періодичності обслуговування найменш надійного засобу.

Вирішальне правило визначення періоду обслуговування кожного засобу можна записати так:

$$
\left|\mathrm{KT}_{\min }^{*}-\mathrm{T}_{\mathrm{i}}^{8}\right| \rightarrow \min
$$

Умова (11) трансформується у вибір для кожного засобу деякого допустимого значення

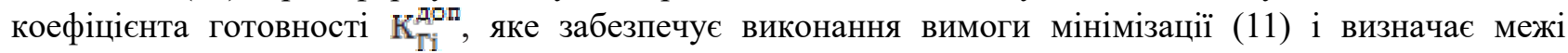
допустимого значення періодичності обслуговування $\mathbb{T}_{i}^{\text {доп }}$. Значення $\mathbb{T}_{i}^{\text {дол }}$ визначається 3 того, що коефіцієнт готовності засобу буде не менше деякого допустимого значення, тобто $\mathrm{K}_{\Gamma \mathrm{i}} \geq \mathrm{K}_{\Gamma \mathrm{ji}}^{\text {доп }}$.

На рис. 2 як приклад показані результати чисельного експерименту з визначення залежності $\mathrm{K}_{\Gamma}(\mathrm{T})$ для трьох засобів з різною надійністю.

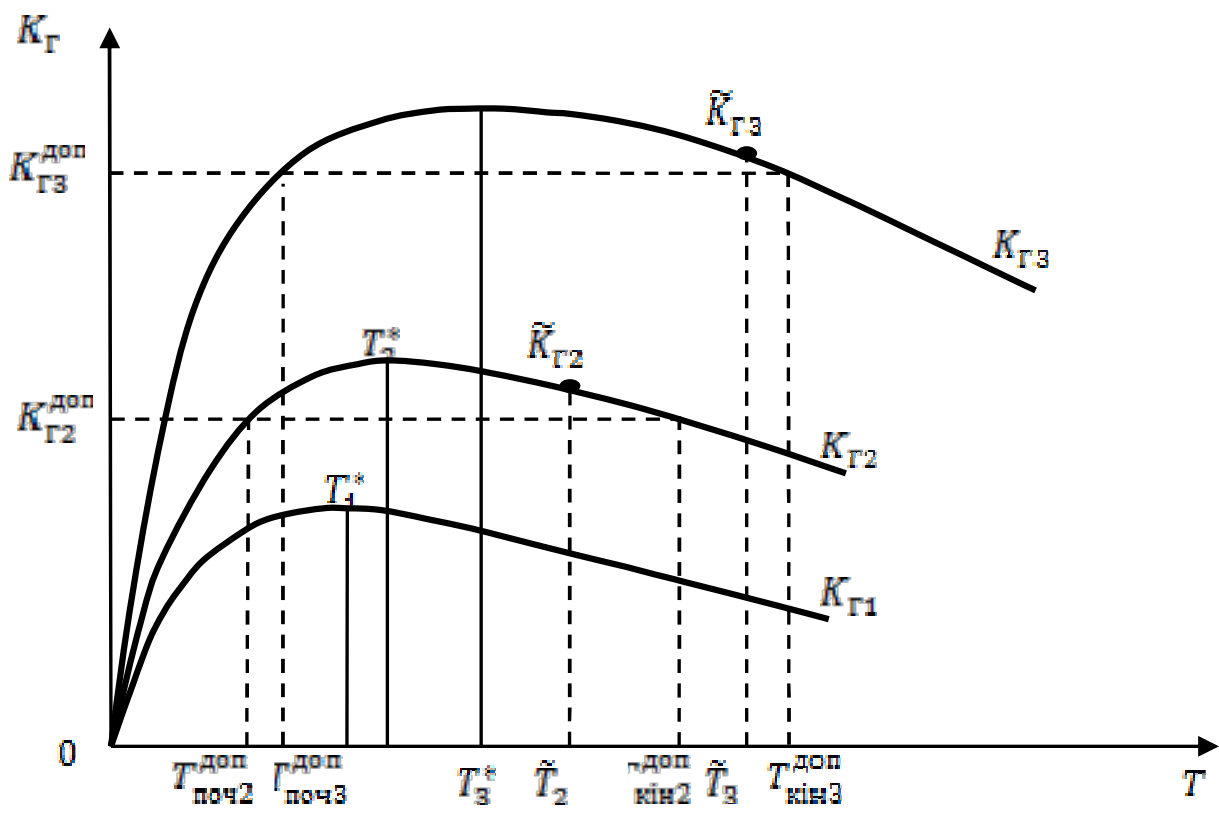

Рис. 2. Результати чисельного експерименту з визначення залежності $\mathbf{K}_{\Gamma}(\mathbf{T})$

3 наведеного прикладу видно, що деяке відхилення значення $\mathbb{K}_{\Gamma і}$ від максимального $\mathbb{K}_{\Gamma i}^{8}$ дозволяє розширити область допустимих значень періодичності обслуговування $\mathrm{T}_{i}^{\text {доп }}$. Значення $\mathrm{K}_{\Gamma i}^{\text {доп }}$ можна визначити як деяку частину $0<\mu \leq \mathbb{1}$ від максимального значення, тобто $\mathrm{K}_{\mathrm{Ti}}^{\text {доп }}=\mu \mathrm{K}_{\Gamma \mathrm{i}}^{*}$. При цьому $\mathrm{T}_{i \mathrm{i}}^{\text {доп }}$ не обмежується тільки оптимальним значенням $\mathrm{T}_{\mathrm{i}}^{8}$, а буде знаходитися в інтервалі 
$\mathrm{T}_{\text {почі }}<\mathrm{T}_{\mathrm{i}}^{\text {доп }}<\mathrm{T}_{\text {кіні }}$, де $\mathrm{T}_{\text {почі }}=\mathrm{T}_{\mathrm{i}}^{*}-\Delta \mathrm{T}_{1 \mathrm{i}} ; \mathrm{T}_{\text {вік і }}=\mathrm{T}_{\mathrm{i}}^{*}-\Delta \mathrm{T}_{2 \mathrm{i}}$. Це дозволяс обчислити значення періодичності обслуговування $\widetilde{\mathbb{T}}_{\mathrm{i}}$, що забезпечить функціонування цих засобів з коефіцієнтом готовності $\widetilde{\mathrm{K}}_{\mathrm{\Gamma i}} \geq \mathrm{K}_{\mathrm{\Gamma i}}^{\text {gоп. }}$.

Переважною для визначення $\widetilde{\mathrm{K}}_{\mathrm{\Gamma i}} \epsilon$ область значень $\mathbb{T}_{i}^{\text {доп }}$, яка обмежена оптимальним значенням $\mathrm{T}_{\mathrm{i}}^{8} \mathrm{i}$ максимально допустимим $\mathrm{T}_{\text {кї }}$, тобто $\mathrm{T}_{\mathrm{i}}^{*} \leq \widetilde{\mathrm{T}}_{\mathrm{i}} \leq \mathrm{T}_{\text {кїні ї }}$ У цій області досягається необхідна готовність разом з більшою періодичністю обслуговування. Оскільки періодичності обслуговування окремих засобів знаходяться з умови кратності, то цим забезпечується раціональне в організаційному розумінні обслуговування засобів СТС.

\section{Висновки}

У статті розглянуто розв'язування задачі визначення узгодженої (компромісної) періодичності технічного обслуговування засобів складної технічної системи. Існує план застосування, що включає інтервали часу застосування системи за призначенням та інтервали, в яких засоби системи вільні від ïx застосування (інтервали очікування). Організація експлуатації передбачає визначення раціональних або оптимальних термінів технічного обслуговування, які забезпечують максимально можливу готовність засобів до застосування. Кількісні показники складності, надійності i ремонтопридатності засобів різні, тому і оптимальні періоди їх обслуговування різні. У статті запропонована методика, що дозволяє визначати раціональну програму технічного обслуговування засобів складної технічної системи.

\section{Список використаних джерел}

1. Любченко, А. А. Анализ процессов технического обслуживания элементов сложных технических систем [Текст] / А. А. Любченко // Информационные технологии, автоматика, связь, телекоммуникации. - 2011. - Вып. 1(5). - С. 88-94.

2. Дьяков, А. Н. Методика выбора стратегии технического обслуживания и ремонта ракетнокосмической техники [Електронний ресурс] / А. Н. Дьяков, С. Кокарев, Д. В. Решетников // Современные проблемы науки и образования. - 2015. - № 2-2. - URL : http://www.scienceeducation.ru/ru/article/view? id=21650 (дата звернення : 26.04.19). - Назва з екрана.

3. Писаренко, В. Н. Оптимизация технического обслуживания стареющих газоперекачивающих агрегатов компрессорных станций [Електронний ресурс] / В. Н. Писаренко, С. П. Королёва // Транспорт. Хранение нефти и газа. - 2015. - Т. 13. - № 2. - C. 105-110. - URL : http://ngdelo.ru/files/old_ngdelo/2015/2/ngdelo-2-2015-p105-110.pdf 21650 (дата звернення : 26.04.19). Назва $з$ екрана.

4. Айденов, В. Г. Методический подход к корректировке периодичности технического обслуживания сложных радиоэлектронных систем по результатам контроля процесса их эксплуатации [Електронний ресурс] / В. Г. Айденов, М. А. Котов, Е. В. Першин // Вооружение и экономика. - 2016. - Вып. 4(37). - C. 46-56. - URL : https://elibrary.ru/item.asp?id=27470637 21650 (дата звернення : 26.04.19). - Назва з екрана.

5. Кривошапов, С. И. Методика корректирования периодичности технического обслуживания транспортных машин [Текст] / С. И. Кривошапов // Вістник ХНТУСГ ім. П. Василенко. - 2015. Вип. 163. - С. 105-110.

6. Лисунов, Е. А. Оптимизация периодичности технического обслуживания и ремонта мобильной техники [Електронний ресурс] / Е. А. Лисунов // Международный журнал прикладных и фундаментальных исследований. - 2017. - № 2-2. - C. 165-167. - URL : https://appliedresearch.ru/ru/article/view?id=11237 (дата звернення : 26.04.19). - Назва з екрана.

7. Шаманов, В. И. Методы оптимизации технического обслуживания систем автоматики [Текст] / В. И. Шаманов // Автоматика на транспорте. - 2016. - № 4. - Т. 2. - С. 481-490.

8. Ефимов, А. В. Оптимизация периодичности ремонтов оборудования энергообъектов с учетом фактора старения систем [Текст] / А. В. Ефимов, Т. В. Потанина // Вісник НТУ “ХПІ". - 2014. № 12(1055). - C. 77-82. 
9. Надежность технических систем [Текст] : справочник / Ю. К. Беляев, В. А. Богатырев, В. В. Болотин и др. ; под ред. И. А. Ушакова. - Москва : Радио и связь, 1985. - 608 с.

10. Барзилович, Е. Ю. Модели технического обслуживания сложных систем [Текст] : учеб. пособие / Е. Ю. Барзилович. - Москва : Высш. шк., 1982. - 231 с.

Стаття надійшла до редакиії 10.04.2019 p.

\title{
УДК 519.87
}

\author{
А. А. Морозов
}

\section{МЕТОДИКА ОПРЕДЕЛЕНИЯ ПЕРИОДИЧНОСТИ ТЕХНИЧЕСКОГО ОБСЛУЖИВАНИЯ СРЕДСТВ СЛОЖНОЙ ТЕХНИЧЕСКОЙ СИСТЕМЫ}

В статье рассмотрена задача определения периодичности технического обслуживания средств сложной технической системы, предложена методика ее решения. Показано, что в условиях, когда средства системы имеют разные уровни надежности и, как следствие, разные периодичности технического обслуживания, обеспечение заданных режсимов функиионирования системы требует нахождения компромиссного периода обслужсивания для всех средств. Предлагается обслуживать средства системь с периодичностью, кратной периоду обслуживания наименее надежного средства. Предложено решающее правило определения периодичности обслуживания каждого средства для определения некоторого допустимого значения коэффичиента его готовности $u$ гранищы допустимого значения периода обслуживания. Значение такого периода определяется из того, что коэффичиент готовности средства будет не меньше некоторого допустимого значения.

Ключ е в бл е сл о в а: сложная техническая система, средства системы, техническое обслуживание, периодичность технического обслуживания, решающее правило, коэффициент готовности, режимы функиионирования.

\section{UDC 519.87}

\section{O. O. Morozov}

\section{METHOD OF DETERMINATION OF PERIODICITY OF TECHNICAL SERVICE OF MEANS OF COMPONENT TECHNICAL SYSTEM}

The article deals with the problem of determining the periodicity of technical maintenance of the component technical system, the method of its solution is proposed. The case in which the means of the system provide the specified modes of its functioning (use) by timely service is considered. At the same time, the means themselves have different modes of operation (application). Malfunction or delayed maintenance of means may adversely affect the operation (use) of the system itself. It is shown that under conditions when the system means have different levels of reliability and, as a result, different maintenance intervals, ensuring the specified operating modes of the system requires finding a compromise periodicity of their maintenance.

Great number of values for optimal service periods, corresponding to a multitude of means, form such a set of maintenance cycles that its practical implementation is irrational. Consequently, there is a need to regulate the set of maintenance cycles of means by finding a compromise, close to optimal, the values of the maintenance period of all means of the system. It is obvious that such a compromise is a reflection of the decision rule, which must be introduced informally and determine itself the permissible divergence of the values of the means maintenance periods from the optimal values of the periodicity of means maintenance. $A$ rule for choosing the period for maintenance of means is offered. It is shown that from the point of view of ordering the terms of means maintenance, the multiplicity of periods of their maintenance is acceptable.

It is proposed to maintain the means of the system with periodicity that is multiple to the service period of the least reliable means. A decision rule has been proposed for determining the maintenance period of each 
facility, which determines the choice for each means of a certain admissible value of its availability factor and for determining the limit of the allowable service period for each facility. The value of such a period is determined by the fact that the availability factor of the means will not be less than a certain acceptable value.

By the example of three means with different level of reliability, the applicability of the proposed method is shown. Calculations show that a certain deviation of the value of the means availability factors from their maximum values allows expanding the range of acceptable values for the maintenance period. Admissible values can be defined as a certain part of maximum value of the availability factor. It is shown that the permissible periodicity of maintenance of means is not limited to only the optimal value, but can be in a certain interval. This allows determining of the values of maintenance periods of means that will ensure their operation with the required availability factor.

For determining compromise availability factors the range of permissible values of the service intervals of means, limited by the optimal value of the periodicity of maintenance and the maximum admissible, is preferred. Calculations show that in this area the required availability is achieved with a greater periodicity of service. Since the periods of maintenance of separate means are found from the multiplicity condition, this ensures an organizationally rational maintenance of the means of a component technical system.

$K$ e $y$ w o $r d$ s: component technical system, system means, maintenance, maintenance periodicity, decision rule, availability factor, operating modes.

Морозов Олександр Олександрович - доктор технічних наук, професор, перший заступник начальника Національної академії Національної гвардії України з навчально-методичної та наукової роботи.

http://orcid.org/0000-0002-1352-1783 